\title{
Fragment edge and isolation affect the food web: effects on the strength of interactions among trophic guilds
}

\author{
Michele Molina Melo ${ }^{I}$, Cristina Magalhães Silva ${ }^{I}$, Carina Santos Barbosa ${ }^{\mathbb{1}}$, Maristela Calvente Morais ${ }^{1}$, \\ Paula Eveline Ribeiro D’Anunciação ${ }^{2}$, Vinícius Xavier da Silva ${ }^{1}$ \& Érica Hasui, ${ }^{1,3}$ \\ ${ }^{1}$ Universidade Federal de Alfenas, Instituto de Ciências da Natureza Alfenas, MG, Brazil. \\ ${ }^{2}$ Universidade Federal de Lavras, Departamento de Biologia, Setor de Ecologia, Lavras, MG, Brazil. \\ ${ }^{3}$ Corresponding author: Érica Hasui, e-mail: ericahasui@yahoo.com
}

MELO, M.M., SILVA, C.M., BARBOSA, C.S., MORAIS, M.C., D’ANUNCIAÇÃO, P.E.R., SILVA, V.X., HASUI, E. Fragment edge and isolation affect the food web: effects on the strength of interactions among trophic guilds. Biota Neotropica. 16(2): e20150088. http://dx.doi.org/10.1590/1676-0611-BN-2015-0088

\begin{abstract}
Habitat loss and fragmentation are processes that may affect communities by changing species interactions. These changes occur because the strength of linkages between species is not exclusively dependent on predator and prey traits. Species interaction changes also depend on the spatial context in which they take place. We used structural equation modelling to evaluate effects of these processes at patch-scale on top-down and bottom-up controls in food webs in Atlantic Forest. The model was composed of multiple species, and trophic guilds responded differently to fragment edge and isolation. Changes in bottom-up and top-down controls were mainly related to intermediate predator interactions. Efforts to restore connectivity among fragments should help recover the equilibrium of the trophic interactions by benefiting intermediate predators.
\end{abstract}

Keywords: Atlantic Forest; bird; Brazil; connectivity; landscape; mammal; patch-scale; patch size; predator-prey interaction; trophic cascade.

MELO, M.M., SILVA, C.M., BARBOSA, C.S., MORAIS, M.C., D’ANUNCIAÇÃO, P.E.R., SILVA, V.X., HASUI, E. Borda e isolamento dos fragmentos afetam a cadeia alimentar: efeitos sobre a força de interação entre guildas tróficas. Biota Neotropica. 16(2): e20150088. http://dx.doi.org/10.1590/1676-0611-BN2015-0088

Resumo: A perda e fragmentação de habitats podem afetar as comunidades através das mudanças nas interações entre espécies. Isso ocorre porque a força das ligações entre espécies não depende exclusivamente das características das espécies envolvidas, mas mudam dependendo do contexto espacial em que elas ocorrem. Usamos modelagem de equações estruturais para avaliar efeitos destes processos sobre o controle top-down e bottom-up nas teias alimentares em Mata Atlântica, na escala das manchas de habitats. O modelo foi composto com várias espécies. As guildas tróficas responderam de forma diferente ao efeito do isolamento e da borda dos fragmentos. Mudanças nos controles bottom-up e topdown foram principalmente relacionadas com as interações envolvendo os predadores intermediários. Esforços para restaurar a conectividade entre os fragmentos devem ajudar na recuperação do equilíbrio das relações tróficas, beneficiando predadores intermediários.

Palavras-chave: aves; Brasil; cascata trófica; conectividade; escala ao nível da mancha; interação predadorpresa; Mata Atlântica; mamíferos; paisagem; tamanho da mancha.

\section{Introduction}

Understanding how habitat loss and fragmentation affect the structure and dynamics of communities is vital for theoretical and applied conservation given the accelerated rate of deforestation around the world. Empirical evidence suggests that fragmentation and habitat loss affect communities by altering species interactions (Sinclair et al. 2003). Species interactions are disrupted because the strength of linkages between trophic levels is not exclusively dependent on predator and prey traits. They also change depending on the spatial context in which the interactions take place (Morrison et al. 1992, Didham et al. 1996, Henle 2004, Terborgh et al. 2010). Thus, habitat fragmentation changes this context and consequently, modifies the interactions between species.

In addition, species in food webs do not respond uniformly to fragmentation. Many derived features of demography, optimal foraging, and life history have been suggested to influence sensitivity to fragmentation (Henle et al. 2004, Meyer et al. 2008). In this respect, top predators seem to be more vulnerable to fragmentation than other trophic guilds 
(Pauly et al. 1998, Dobson et al. 2006), and several traits have been suggested to cause this pattern. First, top vertebrate predators are usually large and tend to require more resources (area and food), and consequently, they are more likely to have their habitat destroyed. Second, large predators (e.g. felines) are often in high conflict with humans, leading to purposeful hunting by people (Stewart 1985, Carey and Peeler 1995, Sick, 1997, Marks \& Canning 1999). Lastly, large predators have low densities and more unstable population dynamics (Henle et al. 2004). Thus, the top levels are the first to lose species. The topdown cascade hypothesis was proposed as a possible mechanism to explain the consequences of the disappearance of top predators in communities (Crooks \& Soulé 1999, Wangchuk 2004). The extinction of top predators may have overwhelming effects that propagate across more than one trophic link in a food web, resulting in inverse patterns in abundance or biomass in the trophic levels involved, e.g. an increase in smaller predators (mesopredators) and a decrease in primary consumers (Paine 1966, Holt \& Loreau 2002, Ives et al. 2005). On the other hand, a bottom-up cascade describes the alteration in food-web components by the reduction of primary producers or the input of limiting nutrients to an ecosystem (Pace et al. 1999). Theoretically, the balance between top-down (predator acting as a major force in controlling community structure) and bottom up dynamics (primary producer or primary consumer acting as a major force in controlling community structure) explains the structure and function of the ecosystem (Frank et al. 2005).

Although the existence of trophic cascades is well accepted (Pace et al. 1999), their prevalence in terrestrial food webs is still debated. Previous studies suggest that trophic cascades may be restricted to less diverse communities (Strong 1992). Conversely, in highly diverse communities, food webs are diffuse, involving numerous species at both producer and consumer levels. Diffuse webs are redundant and create weak links between trophic levels, where the addition or removal of species results in minor adjustments elsewhere in the system and consequently, weak trophic cascades (Terborgh \& Feeley 2010). However, recent empirical studies (Beschta \& Ripple 2009, 2011) demonstrated the existence of strong trophic cascades in highly diverse communities.

However, critics pointed out that published examples of terrestrial trophic cascades generally involve smaller subsets of the food web (often single species per trophic level) when compared to cascades that occur in aquatic habitats (Nee et al. 1997, Bascompte \& Sole 1998, Rushton et al. 2000, Nakagiri et al. 2001, Schneider 2001, Swihart et al. 2001, Prakash \& De Roos 2002, Kondoh, 2003, Nakagiri \& Tainaka 2004).

In our study, we used structural equation modelling (SEM) with multiple species at each level to evaluate the effect of forest fragmentation on top-down and bottom-up trophic cascades using a patch scale approach. This method allows the inclusion of interactions within food webs and the conditions for coexistence of species within trophic levels (Holt et al. 2010). Furthermore, SEM evaluates multiple direct and indirect pathways that operate simultaneously among trophic levels (Iriondo 2003). For a better understanding of the SEM process, two different types of causal relationships can be described: direct causal relationship, where one variable directly causes an effect on the other, and indirect causal relationship, where one variable causes an effect on another through a third variable.
We tested two hypotheses about how fragmentation and habitat loss affect the strength of trophic cascades in fragmented forest habitats by considering four patch metrics (i.e. area, shape complexity, connectivity, and isolation) that together describe the spatial attributes of individual patches in fragmented landscape. Hypothesis 1: Area and isolation effects: smaller and more isolated fragments are expected to harbour the lowest species diversities, due to population collapse arising from limited resources in small patches and impaired extinction rescue in isolated ones (Brown \& Kodric-Brown 1977, Fahrig 2003, Ewers \& Didham 2006). Thus, a lower diversity, indicated by fewer redundant links and less reticulate food webs, should strengthen trophic cascades. In addition, area and isolation are expected to differentially influence the different trophic levels. As a result, top predators are not expected to occur in small and isolated fragments (Schoener \& Spiller 2010). Hypothesis 2: Edge effect: Fragments with complex shapes (i.e. a patch with irregular geometry) have a higher edge: core ratio (Ewers \& Didham 2006). Additionally, shapes with a high complexity may decrease the amount of core habitat available. As a result, the top-down effect of specialist predators on their prey that live only in core habitats also decreases. These effects decrease the per capita effect of predators, i.e. the individual risk of predation decreases. However, the opposite can occur if generalist predators are incorporated in the food web. These predators are matrix tolerant or live primarily in the matrix, but readily occupy forested habitats.

Specifically, we addressed the two following questions: i) What is the influence of patch metrics on food webs, considering both direct and indirect effects? ii) Is there evidence for trophic cascades in forest fragment habitats? If so, what patch metrics are most relevant in this process?

\section{Materials and methods}

\section{Study area and landscape analysis}

We conducted this study in nine fragments of Atlantic Forest from January to November 2011 in Alfenas, Minas Gerais, south-eastern Brazil (21 $1^{\circ} 25^{\prime} 48.03^{\prime \prime}$ S, $45^{\circ} 56^{\prime} 51.76$ " W; $880 \mathrm{~m}$ a.s.l.; Figure 1, Appendix 1). The average annual temperature and relative humidity are $23^{\circ} \mathrm{C}$ and $70 \%$, respectively with an evenly distributed annual rainfall averaging $1600 \mathrm{~mm} / \mathrm{year}$. The original vegetation is classified as seasonal semideciduous forest. (Drummond et al. 2005, Martins et al. 2006). However, this vegetation has been drastically reduced in this region ( $3 \%$ forest cover, Capobianco 2001) and consist of small and sparse fragments at several successional stages ( $97 \%$ of fragments are $<50$ ha, Hasui E. unpublished data). The landscape matrix is mainly composed of coffee plantations, but also has pastures and plantations growing sugar cane, limens, tangerines, garlic, bananas, tomatoes, potatoes, and rice (Fundação SOS Mata Atlântica \& Instituto Nacional de Pesquisas Espaciais 2010, IBGE 2010).

In order to analyse the patch metrics, we conducted a preliminary analysis to select fragments for sampling. We digitally processed multispectral images generated by the CCD sensor of the CBERS-2B satellite, which has a $20 \mathrm{~m}$ resolution. We identified old growth forest fragments and water bodies within a $30 \mathrm{~km}$ radius of Alfenas, using the spectral mixture model satellite (Souza 2006). This model expresses the amount of shade, soil, green vegetation, and nonphotosynthetic vegetation within each 


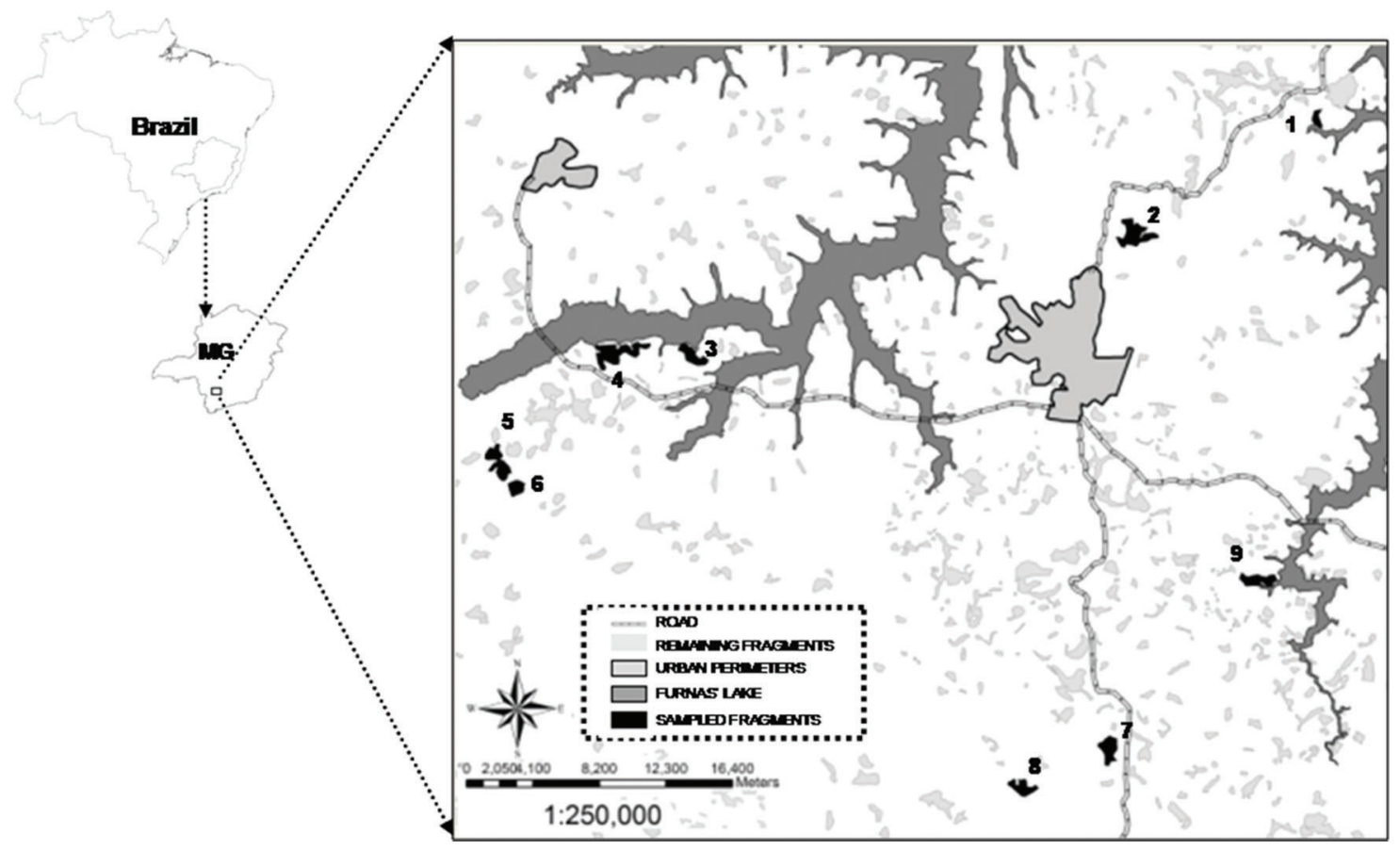

Figure 1. Location of fragments studied (dark coloured) in the surroundings of Alfenas, Minas Gerais (MG). The inset shows the fragmented landscape with the sampled fragments in black.

pixel of the image and enables the separation of forest and nonforest pixels (i.e. pasture, plantation, and water classes). Among forests, it is also possible to discriminate forest regeneration and secondary forests based on the structure, texture and colour of the pixel sets belonging to each patch. Then, we calculated the following patch metrics using the Fragstats program: AREA, SHAPE, ENN, and PROX (McGarigal et al. 2002).

AREA (Area) equals the patch area $\left(\mathrm{m}^{2}\right)$, converted to hectares.

SHAPE (Shape Index) is calculated from the ratio of the perimeter to area of the patch. The perimeter for the most compact patch of the same patch area has a circular form, and the SHAPE index is equal to one. This value increases without limit as the shape becomes more complex.

ENN (Euclidean Nearest-Neighbour Distance) is defined as the shortest straight-line distance (in meters) between the focal patch and its nearest neighbour patch. This nearest neighbour was not sampled, to guarantee the independence of sampled data. The index varies from zero to infinity. High values indicate isolated patches.

PROX (Proximity Index) also quantifies patch connectivity. However, this index considers the size and proximity of all patches within a specified search radius (i.e. $1000 \mathrm{~m}$ in our study). If the focal patch has no neighbours of the same type within the radius, PROX equals zero, increasing as patches become closer and more contiguous.

For fieldwork and further analysis, we selected nine fragments (Appendix 1) that were at least $2 \mathrm{~km}$ distant from each other that had similar altitude, water availability, and were at a similar successional stage (i.e. were old growth forests). By choosing fragments with these characteristics, we hoped to eliminate possible effects of water availability and successional stages on species richness. Where possible, we chose patches that increased the range of patch metrics in the sample design.

\section{Sampling methods and statistical analysis}

We used a standardised sampling protocol in the nine fragments, taking the same number of samples during the same period (from January to November 2011) regardless of patch metrics. We used three methods to sample species: 1) pitfall traps to assess rodent biomass, 2) playbacks to measure owl species richness, and 3) interviews of local residents to determine species richness of medium and large mammals.

Rodents were collected using five pitfall traps (Corn 1994) arranged along a single line transect, spaced at $30 \mathrm{~m}$ intervals between each other and $50 \mathrm{~m}$ from the edge of the fragment. Each trap consisted of four 301 buckets buried to ground level and connected by a $4 \mathrm{~m}$ fence guide ( $50 \mathrm{~cm}$ high). We collected samples from January to March of 2011, leaving the buckets open for 15 continuous days and checking them daily. We weighed rodents and noted where they were captured, but we did not identify them to the species level. Each specimen collected was euthanized and subsequently frozen.

We obtained owl species richness estimates using playbacks (Boscolo et al. 2006) and visual identification of species whenever possible. Eight owl species, known to occur in the study area (Sigrist 2006), were selected a priori: Glaucidium minutissimun, Glaucidium brasilianum, Strix virgata, Strix hylophila, Pulsatrix koeniswaldiana, Bubo virginianus, Athene cunicularia, and Megascops choliba. They inhabit forested habitat (Amaral 2007), but the degree of forest dependence varies between species. We classified the owls as medium-sized predators, because they mostly eat small mammals, and occasionally other vertebrates and/or insects (Amaral 2007). Furthermore, they respond very well to playback of conspecific vocalisations (Galeotti and Pavan 1993). Playback sequences consisted of a $1 \mathrm{~min}$ of vocalisation, followed by a 2 min interval of silence, and then a repeat of the playback if an owl responded so as to identify the species with higher certainty (Johnson et al. 1981). Vocalisations were played 
in increasing order of species size to reduce interference by larger owls with smaller ones. Vocalisations were played between 6:00p.m. and 10:00p.m., when owls are most active. Playbacks were played at three points along the transect in each fragment, at a minimum distance of $50 \mathrm{~m}$ from the edge and $300 \mathrm{~m}$ from each other to ensure sample independence. Playbacks were conducted twice (Bibby et al. 1992).

We obtained estimates of mammal species richness using interviews that were composed of open questions about mammal species occupancy in fragments, accompanied by species pictures (Michalski \& Peres 2005). We divided the species into two classes based on prey weight consumption: medium- (typically weighing $<1 \mathrm{~kg}$ ) and large (mostly 1 to $10 \mathrm{~kg}$ ) (Konecny 1989, Costa et al. 2004, Gatti et al. 2006, Moreno et al. 2006, Azevedo \& Murray 2007). To assess the frequency of type I or type II errors in the interviews, local informants were asked to identify which species were present in the patch from a selection of mammal pictures, including species known not to occur in the study area as a negative control. We obtained estimates of mammal species richness using interviews, five per fragment, that were usually long-term workers or landowners familiar with mammals inhabiting fragments.

For statistical analysis, we used structural equation modelling (program AMOS 5.0, Arbuckle 2003) to test hypotheses about the influences of patch metrics on food webs. We used this test because it allows one to test a set of regression equations simultaneously. The individual causal mechanisms between predators and their prey were represented in a path diagram (Didham et al. 1996).

We tested four hypotheses based on patch metrics (area, shape, connectivity, and isolation) that potentially explain topdown and bottom-up controls in predator-prey relationships.

1. Patch size (AREA). Larger predators only occupy large fragments and are expected to decrease the impact of mesopredators (Henle et al. 2004). In contrast, large predators would be rare in smaller fragments due to reduced carrying capacity (Terborgh et al. 2010). As a result, we expected a stronger trophic cascade effect of top-predator reduction in smaller fragments.

2. Shape complexity (SHAPE). We hypothesised that fragments with more complex shape are more prone to edge effects, which increase the loss of top predators restricted to forested areas. On the other hand, species that are not exclusively from forest habitat, using the matrix as a second habitat, are benefited. The reason is that, with the absence of top predators, they are released from predation control and are not negatively affected by edge effects (Laurence \& Bierregard 1997).

3. Connectivity (PROX). We expected that top predators' vulnerability to extinction increases in less connected fragments (Michalski \& Peres 2005). Thus, more connected fragments should have more reticulated food webs and less evidence of trophic cascades.

4. Isolation (ENN). Isolation affects metapopulation sourcesink dynamics, as the increase of isolation stops the movement of species between habitats. This should destabilise the trophic dynamics, as the diversity of each level will be poor as will the interaction between them (Holt 1984). Thus, we expected lower species richness in isolated fragments and consequently, increased evidence of trophic cascades (Schoener \& Spiller 2010).
We log-transformed the variables to obtain data homoscedasticity before performing further statistical analyses. All model parameters were estimated using maximum likelihood and the models were compared with the Akaike Information Criterion (AIC). Models with $\triangle \mathrm{AIC}>2$ indicated differences in likelihood. We also used chi-squared likelihood tests to assess the robustness of models. A non-significant result in this test is equivalent to an appropriate model, i.e. no evidence to reject the null hypothesis that the proposed model is adequate. However, it is generally recommended that the chi-squared test be interpreted with caution and complemented with other goodness-of-fit measures, when data depart from multivariate normality and sample sizes are small (Bollen 1989, Loehlin 1992, Bollen \& Long 1993). Therefore, we also calculated the Bentler and Bonett's normed-fit index (NFI), Bentler's comparative fit index (CFI), and/or the Goodness of Fit index (GFI). Values of GFI range from 0 to 1 , and those higher than 0.9 indicate an acceptable fit (Bollen 1989).

The intensity of the relationships tested are given by $\mathrm{P}$ values (significant or not) as well as the coefficients that accompany every relationship established in the analysis. The higher the coefficient the greater the influence of one variable on the other.

\section{Results}

We found four owl species: Strix virgata, Pulsatrix koeniswaldiana, Athene cuninularia, and Megascops choliba. Two of them are specialists (Strix virgata and Pulsatrix koeniswaldiana), restricted to forested habitats, but both were found in only one fragment. Due to their low abundance, we excluded them from further analysis. So, we just included in further analysis the species that also occur in altered environments, such as at the forest edge, and with low environmental sensitivity (Appendix 2). We found seven medium-large mammal species at different trophic levels: three top predators and four intermediate predators (Appendix 3).

All models seemed to be appropriate and none could be rejected (Tables 1 and 2). However, considering goodness-offit, half the models were below 0.9 , suggesting that they miss important predictors and/or interaction pathways. Thus, patch metrics appeared to be influencing bottom-up control in the food web, through the intrinsic characteristics of the fragments (Figure 2). The most robust models with bottom-up control supported the hypotheses of isolation (ENN) and edge influence (SHAPE), but these effects were different among trophic guilds (Tables 1 and 3, Figure 2). Isolation positively affected the lowest trophic level (rodents, Appendix 4) and negatively affected intermediate and top predators (mammals, Appendix 3). Species richness of generalist owl predators (Appendix 2), which live primarily in the matrix, but can also occur in forested habitats, increased with the edge length/ complexity.

The strength of bottom-up dynamics was affected by isolation. There was a higher biomass of the lowest trophic level (rodents) in more isolated fragments, positively influencing the level above. However, this effect was not propagated up to the third level (Figure 2).

Unlike bottom-up effects, patch characteristics had a weak influence on top-down processes. The best models were composed of connectivity and shape, but the direct effects of these variables on trophic guilds were not significant (Table 2 and 4, Figure 3). Nevertheless, the positive effect of top 
Table 1. Structural equation models for food webs with bottom-up control, ranked from best to worst according to Akaike's information criterion (AIC). $\triangle$ AIC represents the difference in AIC from one model to the one with the lowest AIC value. Path diagrams for the best two models (edge effect and isolation influence) are shown in Figure 2. A chi-squared value with $P>0.05$ means acceptable fit. Goodness-of-Fit index (GFI) $>0.9$ indicates an acceptable fit of the model to the data.

\begin{tabular}{|c|c|c|c|c|c|}
\hline HYPOTHESIS OF BOTTOM-UP CONTROL & AIC & $\Delta \mathrm{AIC}$ & GFI & Chi-squared & $\mathbf{P}$ \\
\hline Edge effect (SHAPE) & 26.671 & 0 & 0.969 & 0.671 & 0.715 \\
\hline Isolation influence (ENN) & 26.980 & 0.309 & 0.956 & 0.980 & 0.613 \\
\hline Patch size influence (AREA) & 28.762 & 2.091 & 0.895 & 2.762 & 0.251 \\
\hline Connectivity influence (PROX) & 29.974 & 3.303 & 0.865 & 3.974 & 0.137 \\
\hline
\end{tabular}

Table 2. Structural equation models for food webs with top-down control. $\triangle \mathrm{AIC}$ is the difference between one model to the model with the lowest AIC value. Path diagrams for the best two models (edge effect and connectivity influence) are shown in Figure 3 . A chi-squared value with $P>$ 0.05 means acceptable fit. Goodness of Fit index (GFI) $>0.9$ indicates an acceptable fit of the model to the data.

\begin{tabular}{|c|c|c|c|c|c|}
\hline HYPOTHESIS OF TOP-DOWN CONTROL & AIC & $\Delta \mathrm{AIC}$ & GFI & Chi-squared & $\mathbf{P}$ \\
\hline Edge effect (SHAPE) & 27.519 & 0 & 0.935 & 1.519 & 0.468 \\
\hline Connectivity influence (PROX) & 28.480 & 0.961 & 0.904 & 2.480 & 0.289 \\
\hline Patch size influence (AREA) & 28.865 & 1.346 & 0.893 & 2.865 & 0.239 \\
\hline Isolation influence (ENN) & 29.229 & 1.710 & 0.883 & 3.229 & 0.199 \\
\hline
\end{tabular}

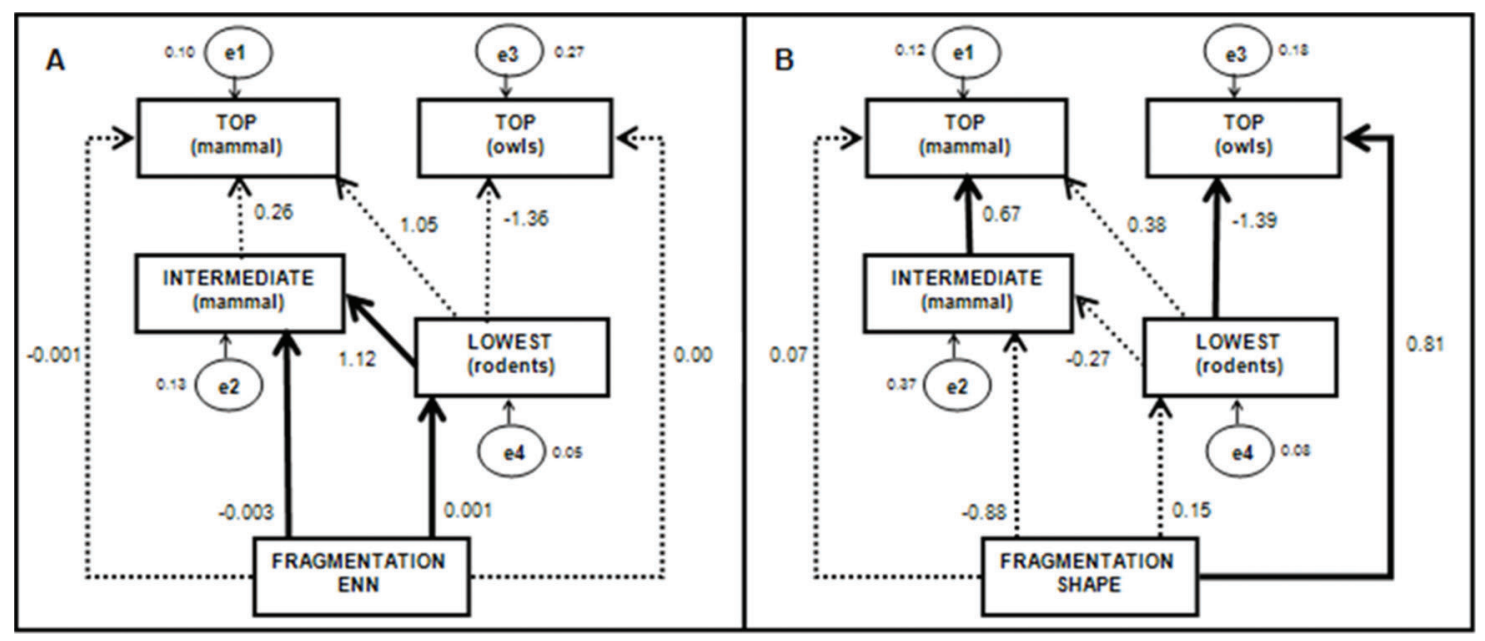

Figure 2. Bottom-up diagram representing the direct and indirect effects of patch metrics on the structure of food webs. Circles indicate error from other factors not considered (e1-e4). Continuous and discontinuous arrows connecting the boxes show significant $(\mathrm{P}>0.05)$ and not significant causal effects, respectively. The numbers next to the arrows indicate correlation values between variables through unstandardized coefficients of path analysis. (A) Direct and indirect effects of the model with bottom-up control on the connectivity of fragments. (B) Direct and indirect effects of the model with bottom-up control on the shape of fragments.

predators on the lower level suggests that the absence of top predators was benefiting the intermediate levels (mammals) and the hypotheses of top-down control of the lowest level (rodents) are supported by the intermediate levels (mammals) and owl predators, which had a negative effect on prey biomass.

\section{Discussion}

Our results suggest that only bottom-up dynamics greatly differ in fragmented landscapes. The biomass of the lowest level (rodents) was higher in more isolated fragments, resulting in positive effects in the levels above. However, this effect was not propagated up through the third level, probably because each trophic guild responded differently to isolation, with intermediate predators being more vulnerable to this factor. Thus, the loss of intermediate species in highly isolated fragments may influence the upper level by reducing prey availability.

There are several processes that may decrease the richness of intermediate predators with increasing isolation. Since distance acts as a filter, more isolated fragments are less likely to receive immigrants from the nearby patch(es) (Fahrig 2013). In addition, isolation can also affect extinction rates. Populations in fragments near others are less prone to extinction because individuals from other fragments can supply the population with individuals from source habitats ("rescue effect", Brown and Kodric-Brown 1977, see also Wolfe et al. 2015). Thus, lower species richness in isolated fragments is often attributed to lower immigration and higher extinction 
Table 3. Influence of edge effect (SHAPE) and isolation (ENN) on each trophic level with bottom-up control. Unstandardized path coefficients are listed for the direct effects of each metric. Unstandardized indirect effects are the products of path coefficients for variables (each trophic level). Total effects are the sum of direct and indirect effects.

\begin{tabular}{llccc}
\hline & \multicolumn{1}{c}{ TROPHIC LEVEL } & DIRECT & INDIRECT & TOTAL \\
\hline ENN & Top (large-sized mammals) & -0.001 & 0 & -0.001 \\
& Top (owls) & 0 & -0.001 & -0.001 \\
& Intermediate (medium-sized mammals) & -0.003 & 0.001 & -0.002 \\
& Lowest (rodents) & 0.001 & 0.001 \\
\multirow{3}{*}{ SHAPE } & Top (large-sized mammals) & 0.066 & -0.555 & -0.489 \\
& Top (owls) & 0.806 & -0.202 & 0.604 \\
& Intermediate (medium-sized mammals) & -0.877 & -0.039 & -0.915 \\
\hline
\end{tabular}

Table 4. Influence of edge effect (SHAPE) and connectivity (PROX) on each trophic level with top-down control. Unstandardized path coefficients are listed for direct effects for each metric. Unstandardized indirect effects are the products of path coefficients for variables (each trophic level). Total effects are the sum of direct and indirect effects.

\begin{tabular}{|c|c|c|c|c|}
\hline & TROPHIC LEVEL & DIRECT & INDIRECT & TOTAL \\
\hline \multirow[t]{4}{*}{ PROX } & Top (large-sized mammals) & 0.016 & 0 & 0.016 \\
\hline & Top (owls) & 0.033 & 0 & 0.033 \\
\hline & Intermediate (medium-sized mammals) & 0.021 & 0.013 & 0.034 \\
\hline & Lowest (rodents) & 0.015 & -0.021 & -0.006 \\
\hline \multirow[t]{4}{*}{ SHAPE } & Top (large-sized mammals) & -0.489 & 0 & -0.489 \\
\hline & Top (owls) & 0.604 & 0 & 0.604 \\
\hline & Intermediate (medium-sized mammals) & -0.505 & -0.41 & -0.915 \\
\hline & Lowest (rodents) & 0.328 & -0.182 & 0.145 \\
\hline
\end{tabular}

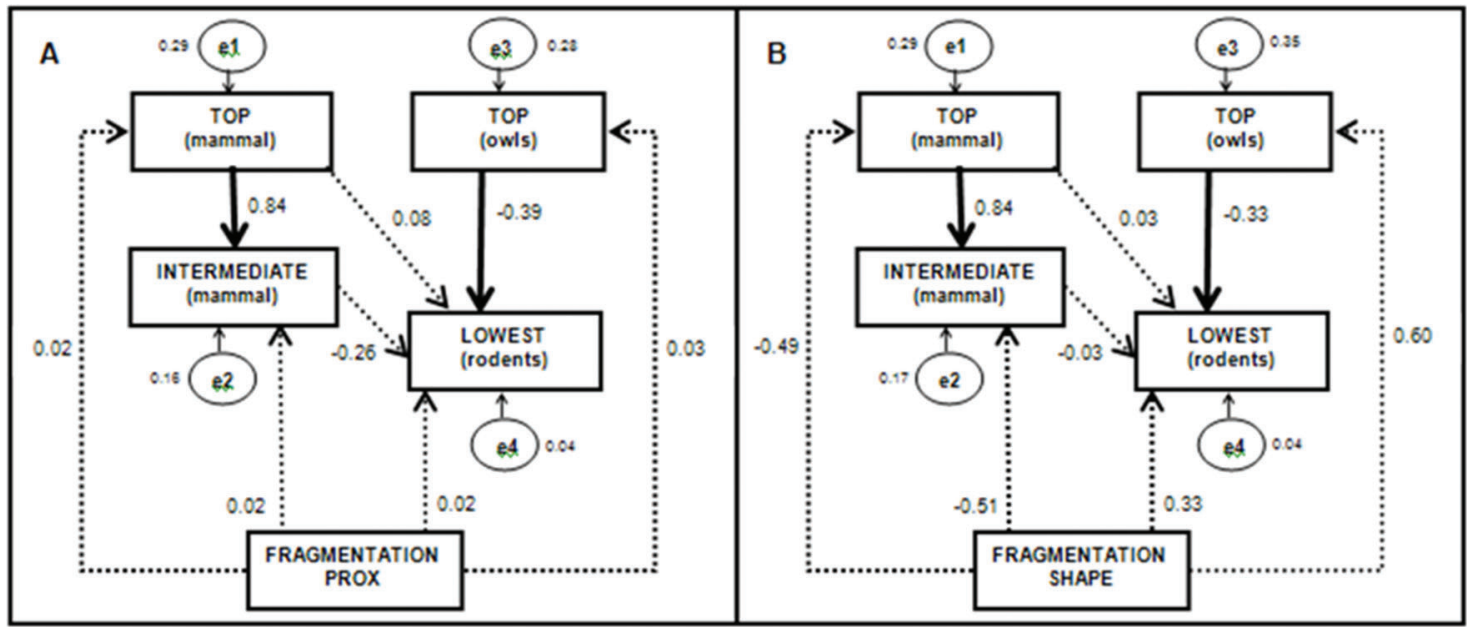

Figure 3. Top-down diagram representing the direct and indirect effects of patch metrics on the structure of food webs. Circles indicate error form other factors not considered (e1-e4). Continuous and discontinuous arrows connecting the boxes show significant $(\mathrm{P}>0.05)$ and not significant causal effects, respectively. The numbers next to the arrows indicate correlation values between variables through unstandardized coefficients of path analysis. (A) Direct and indirect effects of the model with top-down control on the connectivity of fragments. (B) Direct and indirect effects of the model with top-down control on the shape of fragments.

rates. However, it does not explain the positive or lack of responses of top predators (mammals and owls) to isolation. The literature is also full of these conflicting results (see review in Ewers \& Didham 2006) and the reason may be related to the interspecific difference in their dispersal ability in the matrix or habitat preferences. For instance, in our study, most owl species sampled in fragments (e.g. Athene cunicularia and
Megascops choliba) are matrix-based (i.e. live primarily in the matrix, but can also occur in the forest). These species are completely independent of, or respond positively to habitat loss and fragmentation per se, but cause considerable mortality on their prey (rodents; Ryall \& Fahrig 2006).

From a trophic perspective, some of the persistent species in isolated fragments were imbalanced, and others, such as forest 
dependent owls, were probably missing. This suggests a lack of linkages in the food web or a change in the strength of bottom-up and top-down dynamics. Therefore, isolated fragments may be less efficient or productive than habitats with higher species richness. Furthermore, reductions in species richness can weaken interspecific actions (e.g. predation or herbivory), which would in turn weaken trophic dynamics (Otto et al. 2008).

While the loss of linkages can explain an overall weakening in trophic dynamics, it does not explain the distinct response of bottom-up and top-down dynamics to isolation. We found that bottom-up dynamics were mediated by isolation, while topdown dynamics remained unchanged: top predators were not affected (mammals) or benefited (owls) by isolation and fragment edge. Top predators maintained consumption and strengthened top-down control of the level below. However, this was not propagated to the lowest level, because intermediate predators are sensitive to high isolation (Virgós \& García 2002). Predation pressure is directly influenced by predator richness, with lower richness leading to lower predation pressure (Charnov et al. 1976). In this situation, rodent populations could have higher growth rates, since they have partly escaped from predation pressure and in turn, from predator control. In addition, rodents have short life cycles and can keep stable populations even in small patch sizes or in edge habitats (Jordão et al. 2010). Thus, rodents would expand until self-regulation because of resource constraints. However, selfregulation is improbable, because rodents can also use resources from the matrix (McInvaille \& Keith 1974, Crooks \& Soulé 1999, Wangchuk 2004).

The absence of evidence for trophic cascades in forest fragments in our study is in disagreement with Terborgh \& Feeley (2010), who found that top predators were entirely absent from smaller islands. Nevertheless, from the functional perspective, species persistence in fragmented habitat is also imbalanced: there is a higher biomass of rodents, lower richness of intermediate mammal predators, and higher richness of generalist owl predators (matrix-based). These alterations could have influenced bottom-up and top-down controls, mainly related to intermediate predator linkages. Under the weakened top-down control in rodents, vegetation should eventually change in composition and/or structure as a consequence of over-consumption of seeds, making plant recruitment in these fragments severely deficient (Terborgh \& Feeley 2010). Conversely, the weakened bottom-up control between intermediate and top predators should lead to top predators avoiding more isolated fragments, not because they are unable to colonise them, but because their prey are scarce there. One possible implication is that scarce energy can limit the number of trophic levels or the number of species within each trophic level (Zanden et al. 2006).

Linkages between basic food web research and restoration are weak. Nonetheless, they should be effective in nudging ecosystems toward a desired state, in maximising ecosystem services and supporting biodiversity (Dobson et al. 1997). Identifying the main cause of disturbances in predator-prey interactions can help in interventions by removing or managing impacts. Thus, efforts to restore the connectivity between isolated fragments should restore the equilibrium of trophic linkages by benefiting intermediate predators (Clewell et al. 2004, Zanden et al. 2006).

These results concerning the impact of habitat loss and fragmentation on trophic interactions had limitations because our study design was restricted to patch level. There are still many facets in the knowledge that remain unclear. Edge effect is one of them. The matrix-based owl species found in patches may be the result of the increase of the edge in the fragment per unit of core area. This can boost incursion of generalist predators into the fragment. Typically, top predators have higher dispersal ability than intermediate species (Konecny 1989). Thus, top predators can easily predate opportunistically, without being limited or regulated by the abundance of their prey within a single fragment (Marsh \& Trenham 2001, Virgós \& García 2002, Terborgh et al. 2010).

We also do not know whether the matrix structure obscured the patch size effect on trophic interactions (Cook et al. 2002) or whether it was because of the interference of the area by the nearby patch(es) (Fahrig 2013). To resolve these doubts, we recommend a landscape-scale approach in future research, with the inclusion of matrix structure and habitat amount in the analysis. Over larger spatial scales (Pardini et al. 2010), the absence of patch size effects can also be related to the high level of deforestation in our study area (3\% forest cover). To support this explanation, future studies should examine this relationship between patch size and trophic interactions along the regional gradient of landscape degradation.

In summary, fragment isolation and edge complexity interfere directly with trophic interactions by changing species richness and biomass within each trophic level, and also by changing the strength of trophic linkages. Contrary to our expectations, a species' vulnerability to patch features was not related to body size or trophic position. Regardless of the absence of trophic cascades, food webs in more isolated fragments had missing or weakened trophic linkages and need to be restored.

Appendix 1. Patch metrics for nine forest fragments sampled in Alfenas, Minas Gerais, south-eastern Brazil. SAD69: geodetic reference system. UTM: System that describes spatial positions using distance units. Zone 23K: latitudinal zone in which the study area lies.

\begin{tabular}{|c|c|c|c|c|c|}
\hline FRAGMENT & SAD69/ UTM Zone 23K & AREA (ha) & SHAPE & PROX & ENN (m) \\
\hline 1 & $411100.70-7639788.51$ & 15.30 & 1.47 & 5.27 & 361.25 \\
\hline 2 & $402977.76-7615160.99$ & 81.54 & 2.12 & 0.00 & 1068.27 \\
\hline 3 & $383754.52-7630631.59$ & 42.93 & 1.71 & 1.79 & 296.99 \\
\hline 4 & $379121.94-7626339.45$ & 96.03 & 2.46 & 1.66 & 424.26 \\
\hline 5 & $379823.41-7625366.80$ & 63.54 & 2.17 & 32.63 & 94.87 \\
\hline 6 & $399598.25-7613649.98$ & 27.72 & 1.22 & 16.16 & 201.25 \\
\hline 7 & $403980.90-7635268.39$ & 49.68 & 1.47 & 2.23 & 276.59 \\
\hline 8 & $386710.82-7630526.75$ & 38.43 & 1.81 & 0.88 & 496.59 \\
\hline 9 & $408792.94-7621760.03$ & 47.00 & 1.87 & 1.28 & 268.38 \\
\hline
\end{tabular}


Melo, M.M. et al.

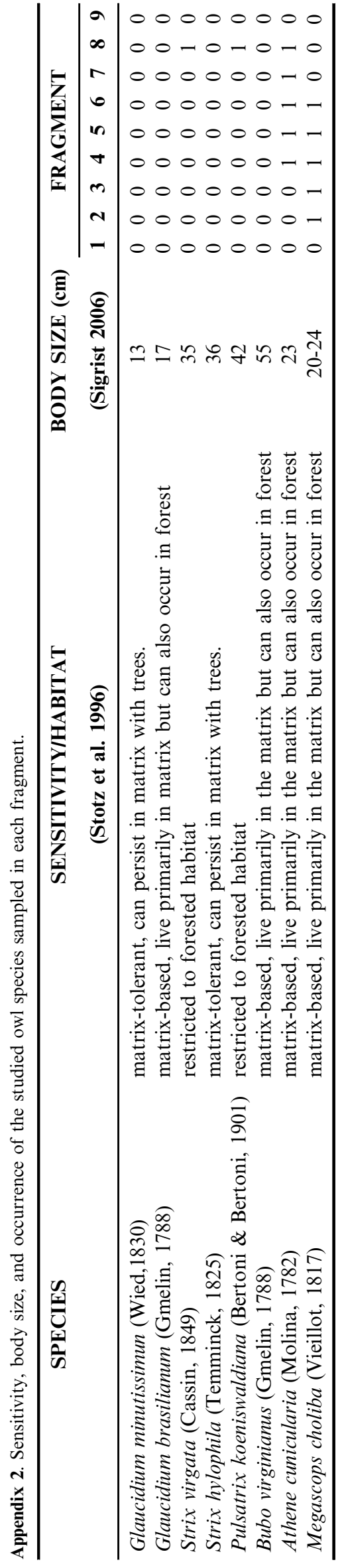

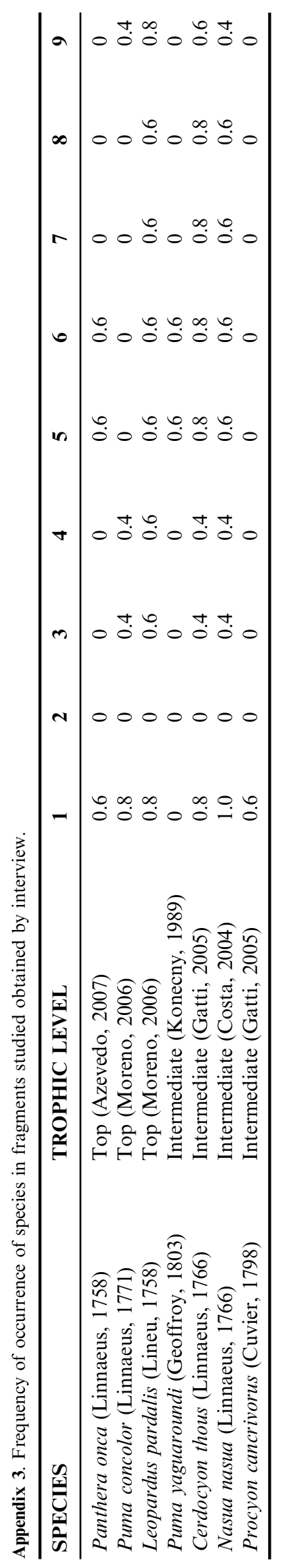

http://dx.doi.org/10.1590/1676-0611-BN-2015-0088 


\section{Acknowledgments}

We wish to express our gratitude to Gregório dos Reis Menezes, Marco Túlio Pacheco Coelho, Lidia Moraes dos Santos, Maísa Ziviani Alves, Cauê Paiva Vidigal Martins, and other members of the Laboratório de Ecologia de Fragmentos Florestais (ECOFRAG/Unifal) who have been valuable friends, assisted in fieldwork, and made essential comments at different phases of this study. This manuscript also greatly benefited from the comments of Flavio Nunes Ramos and Rogério Grassetto Teixera da Cunha. We appreciated the improvements in English language made by Diogo Borges Provete and by Becky Cramer through the Association of Field Ornithologists' programme of editorial assistance. Universidade Federal de Alfenas provided logistical support. We received financial support from Fundação de Amparo à Pesquisa do Estado de Minas Gerais (FAPEMIG) through the Biota Minas Programme (Process \#APQ 03549-09), FAPEMIG-VALE S/A (Process \#RDP-00104-10) and Conselho Nacional de Desenvolvimento Científico e Tecnológico (CNPq) (Process \# 472250/2010). FAPEMIG also provided a Master's scholarship to Paula Eveline Ribeiro D'Anunciação, and Maristela Calvente Morais received an undergraduate scholarship from Programa Institucional de Bolsas de Iniciação Científica (PIBICT) of Universidade Federal de Alfenas (Unifal-MG).

\section{References}

AMARAL, F.K. 2007. Composição e abundância de corujas em Floresta Atlântica e sua relação com variáveis de hábitat. Dissertação de mestrado em Ecologia. Universidade do Rio Grande do Sul, Porto Alegre.

ARBUCKLE, J.L. 2003. AMOS 5.0: Update to the AMOS User's Guide. Smallwaters. Chicago.

AZEVEDO F.C.C. \& MURRAY, D.L. 2007. Spatial organization and food habits of jaguars (Panthera onca) in a floodplain forest. Biol. Conserv. 137:391-402. http://dx.doi.org/10.1016/j.biocon.2007.02.022

BASCOMPTE, J. \& SOLE, R.V. 1998. Effects of habitat destruction in a prey-predator metapopulation model. J. Theor. Biol. 195:83-93. http://dx.doi.org/10.1006/jtbi.1998.0803

BESCHTA, R.L. \& RIPPLE, W.J. 2009. Large predators and trophic cascades in terrestrial ecosystems of the western United States. Biol. Conserv. 142:2401-14. http://dx.doi.org/10.1016/j.biocon.2009.06.015

BESCHTA, R.L. \& RIPPLE, W.J. 2011. The role of large predators in maintaining riparian plant communities and river morphology. Geomorphology, Available from:. http://dx.doi.org/10.1016/j.geomorph. 2011.04.042

BIBBY, C.J. BURGESS, N.D. \& HILL, D.A. 1992. Birds census techniques. London, Academic Press Inc. 312 p.

BOLLEN, K.A. 1989. Structural equations with variables. New York: John Wiley \& Sons. 514 p.

BOLLEN, K.A. \& LONG, J.S. 1993. Testing Structural Equations Model. Thousand Oaks, CA, Sage. 320 p.

BORER, E.T., HALPERN, B.S. \& SEABLOOM, E.W. 2006. Asymmetry in community regulation: Effects of predators and productivity. Ecology 87:2813-20. http://dx.doi.org/10.1890/0012-9658 (2006)87[2813:AICREO]2.0.CO;2

BOSCOLO, D., METZGER, J.P. \& VIELLIARD, J.M.E. 2006. Efficiency of playback for assessing the occurrence of five bird species in Brazilian Atlantic Forest fragments. An. Acad. Bras. Ciênc. 78:629-44. http://dx.doi.org/10.1590/S0001-37652006000400003

BROWN, J.H. \& KODRIC-BROWN, A. 1977. Turnover rates in insular biogeography: effect of immigration on extinction. Ecology 58:445-49. http://dx.doi.org/10.2307/1935620

CAPOBIANCO, J.P.R. 2001. Situação atual e perspectivas para a conservação da Mata Atlântica. In DOCUMENTOS DO ISA, V7.
Aspectos jurídicos da proteção da Mata Atlântica. São Paulo, Instituto Socioambiental. p. 9-16.

CAREY, A.B. \& PEELER, K.C. 1995. Spotted owls: Resource and spaces use in mosaic landscapes. J. Raptor Res. 29(4):223-39.

CHARNOV, E.L., ORIANS, G.H. \& HYATT, K. 1976. Ecological implications of resource depression. Am. Nat. 110(972):247-59. http://dx.doi.org/10.1086/283062

CLEWELL, A., ARONSON, J. \& WINTERHALDER, K. 2004. Fundamentos de Restauração ecológica. Tucson: Society for Ecological Restoration International Science \& Policy Working Group.18p.

COOK, W.M., LANE, K.T., FOSTER, B.L. \& HOLT, R.D. 2002. Island theory, matrix effects and species richness patterns in habitat fragments. Ecology Letters 5, 619-623. http://dx.doi.org/10.1046/j.1461-0248.2002. 00366.x

CORN, P.S. 1994. Standard techniques for inventory and monitoring: straight-line drift fences and pitfalls traps. In HEYER, R., et al. Measuring and monitoring biological diversity: standard methods for amphibians (). Washington and London, Smithsonian Institution Press, p. 109-17.

COSTA, A.P.C., DA FONSECA, A.G. \& CHRISTÓFARO, C. 2004. Variation in the diet of the brown-nosed coati (Nasua nasua) in Southeastern Brazil. Am. Soc. Mammal. 85(3):478-82. http://dx.doi. org/10.1644/1545-1542(2004)085<0478:VITDOT > 2.0.CO;2

CROOKS, K.R. \& SOULE, M.E. 1999. Mesopredator release and avifaunal extinctions in a fragmented system. Nature 400:563-66. http://dx.doi.org/10.1038/23028

DIDHAM, R.K., GHAZOUL, J., STORK, N.E. and DAVIS, A.J. 1996. Insects in fragmented forests: a functional approach. Trends Ecol. Evol. 11:255-60. http://dx.doi.org/10.1016/0169-5347(96)20047-3

DOBSON, A., LODGE, D., ALDER, J., CUMMING, G.S., KEYMER, J. \& MCGLADE, J. 2006. Habitat loss, trophic collapse, and the decline of ecosystem services. Ecology 87:1915-24. http://dx.doi.org/10.1890/0012-9658(2006)87[1915:HLTCAT]2.0. $\mathrm{CO} ; 2$

DOBSON, A.P., BRADSHAW, A.D. \& BAKER, A.J.M. 1997. Hope for the future: Restoration ecology and conservation biology. Science 277:515-22. http://dx.doi.org/10.1126/science.277.5325.515

DRUMMOND, G.M., MARTINS, C.S., MACHADO, A.B.M. \& ANTONINI, Y. 2005. Biodiversidade em Minas Gerais: um atlas para sua conservação. 2nd ed. Belo Horizonte, Fundação Biodiversitas. $94 \mathrm{p}$.

DUFFY, J.E., 2002. Biodiversity and ecosystem function: the consumer connection. Oikos 99:201-19. http://dx.doi.org/10.1034/j.1600-0706.2002. 990201.x

EWERS, R.M. \& DIDHAM R.K. 2006. Confounding factors in the detection of species responses to habitat fragmentation. Biol. Rev. 81:117-42. http://dx.doi.org/10.1017/S146479310500

FAHRIG, L. 2003. Effects of habitat fragmentation on biodiversity. Annu. Rev. Ecol. Evol. Syst. 34:487-515. http://dx.doi.org/10.1146/ annurev.ecolsys.34.011802.132419

FAHRIG, L. 2013. Rethinking patch size and isolation effects: the habitat amount hypothesis. J. Biogeogr. 40:1649-1663. http://dx.doi.org/ 10.1111/jbi.12130

FRANK, K.T., PETRIE, B., CHOI, J.S. \& LEGGETT, W.C. 2005. Trophic cascades in a formerly cod-dominated ecosystem. Science 308:1621. http://dx.doi.org/10.1126/science.1113075

FUNDAÇÃO SOS MATA ATLÂNTICA \& INSTITUTO NACIONAL DE PESQUISAS ESPACIAIS, 2010. Atlas dos remanescentes florestais da Mata Atlântica período 2008-2010. São Paulo, Fundação SOS Mata Atlântica/INPE.

GALEOTTI, P. \& PAVAN, G. 1993. Differential responses of territorial tawny owls Strix aluco to the shooting of neighbour's and strangers. The International Journal of Avian Science 135:300-4. http://dx.doi.org/10.1111/j.1474-919X.1993.tb02847.x

GATTI, A., BIANCHI, R., ROSA, C.R.X. \& MENDES, S.L. 2006. Diet of two sympatric carnivores, Cerdocyon thous and Procyon cancrivorus, in a restinga area of Espirito Santo State, Brazil. J. Trop. Ecol. 22: 227-30. http://dx.doi.org/10.1017/S0266467405 002956 
HENLE, K., KENDI, F.D., KLEYER, M., MARGULES, C. \& SETTELE, J. 2004. Predictors of species sensitivity to fragmentation. Biodivers. Conserv. 13:207-51. http://dx.doi.org/10.1023/B:BIOC.0000 $004319.91643 .9 \mathrm{e}$

HOLT, R.D. 1984. Spatial heterogeneity, indirect interactions, and the coexistence of prey species. Am. Nat. 124(3):377-406. http://dx.doi.org/10.1086/284280

HOLT, R.D., HOLDO, R.M. \& VAN VENN, F.J.F. 2010. Theoretical Perspectives on Trophic Cascades: Current Trends and Future Directions. In Trophic Cascades: Predators, Prey, and the Changing Dynamics of Nature (Terborgh, J. \& Estes, J.A., eds). Washington, Island Press, $488 \mathrm{p}$.

HOLT, R.D. \& LOREAU, M. 2002. Biodiversity and ecosystem functioning: the role of trophic interactions and the importance of system openness. In The Functional Consequences of Biodiversity (Kinzig, A.P., Pacala, S. \& Tilman, D., eds) Empirical Progress and Theoretical Expectations. Princeton: Princeton University Press, p. $246-62$

IBGE. 2010. Banco de Dados Agregados. Sistema IBGE de Recuperação Automática - SIDRA. Available from: http://www.ibge.gov. br/cidadesat/topwindow.htm?1.

IRIONDO, J. 2003. Structural equation modelling: an alternative for assessing causal relationships in threatened plant populations. Biol. Conserv. 113(3):367-77. http://dx.doi.org/10.1016/S0006-3207(03) 00129-0

IVES, A.R., CARDINALE, B.J. \& SNYDER, W.E. 2005. A synthesis of subdisciplines: predator-prey interactions, and biodiversity and ecosystem functioning. Ecol. Lett. 8:102-16. http://dx.doi.org/10.1111/ j.1461-0248.2004.00698.x

JOHNSON, R.R., BROWN, B.T., HAIGHT, L.T. \& SIMPSON, J.M. 1981. Playback recordings as a special avian censusing technique. Stud. Avian. Biol. 6:68-75.

JORDÃO, J.C., RAMOS, F.N. \& SILVA, V.X. 2010. Demographic parameters of Akodon montensis (Mammalia, Rodentia) in an Atlantic Forest remnant of Southeastern Brazil. Mammalia 74:395-400. http://dx.doi.org/10.1515/mamm.2010.045

$\mathrm{KONDOH}$, M. 2003. Habitat fragmentation resulting in overgrazing by herbivores. J. Theor. Biol. 225:453-60. http://dx.doi.org/ 10.1016/S0022-5193(03)00279-0

KONECNY, M.J. 1989. Movement patterns and food habits of four sympatric carnivore species in Belize, Central America. In REDFORD, K.H. \& EISENBERG, J.F. Advances on Neotropical Mammalogy. Florida, Sandhill Crane Press, p. 243-64.

LAURENCE, W.F. \& BIERREGARD, R.O. 1997. Tropical forest remnants: Ecology, Management and Conservation of Fragmented Communities. Chicago: University of Chicago Press, $632 \mathrm{p}$.

LOEHLIN, J.C. 1992. Latent Variable Models. An Introduction to Factor, Path, and Structural Analysis. Hillsdale: Lawrence Erlbaum, 336 p.

MARSH, D.M. \& TRENHAM, P.C. 2001. Metapopulation Dynamics and Amphibian Conservation. Conserv. Biol. 15(1):40-9. http://dx.doi.org/10.1111/j.1523-1739.2001.00129.x

MARTINS, F.T., SANTOS, M.H., POLO, M. \& BARBOSA, L.C.A., 2006. Variação química do óleo essencial de Hyptis suaveolens (L.) Poit., sob condições de cultivo. Química Nova 29(6):1203-9.

MCGARIGAL, K., CUSHMAN, S.A., NEEL, M.C. \& ENE, E. 2002. FRAGSTATS: Spatial Pattern Analysis Program for Categorical Maps. Computer software program produced by the authors at the University of Massachusetts, Amherst. Available from: http:// www.umass.edu/landeco/research/fragstats/fragstats.html

MCINVAILLE-JR, W.B. \& KEITH, L.B. 1974. Predator-prey relations and breeding biology of the great horned owl and the red tailed hawk in Central Alberta. Can. Field. Nat. 88:1-20.

MEYER, C.F.J., FRUND, J., LIZANO, W.P. \& KALKO, E.K.V. 2008. Ecological correlates of vulnerability to fragmentation in Neotropical bats. J. Appl. Ecol. 45:381-91. http://dx.doi.org/10.1111/j.1365-2664. 2007.01389.x

MICHALSKI, F. and PERES, C.A., 2005. Anthropogenic determinants of primate and carnivore local extinctions in a fragmented forest landscape of southern Amazonia. Conserv. Biol. 124:383-96. http://dx.doi.org/10.1016/j.biocon.2005.01.045

MORENO, S.R., KAYS, W.R. \& SAMUDIO-J.R. 2006. Competitive release in diets of ocelot (Leopardus pardalis) and puma (Puma concolor) after jaguar (Panthera onca) decline. J. Mammal. 87 (4):808-16. http://dx.doi.org/10.1644/05-MAMM-A-360R2.1

MORRISON, M.L., MARCOT, B.G. \& MANNAN, R.W. 1992. Wildlife-habitat relationships: concepts \& applications. Madison, University of Wisconsin Press, 448 p.

NAKAGIRI, N., TAINAKA, K.I. \& TAO, T. 2001. Indirect relation between species extinction and habitat destruction. Ecol. Model. 137:109-18. http://dx.doi.org/10.1016/S0304-3800(00)00417-8

NAKAGIRI, N \& TANAKA, K. 2004. Indirect effects of habitat destruction in model ecosystems. Ecol. Model. 174:103-14. http://dx.doi.org/10.1016/j.ecolmodel.2003.12.047

NEE, S., MAY, R.M. \& HASSELL, M.P. 1997. Two-species metapopulation models. In Metapopulation biology, ecology, genetics and evolution (Hanski, I.A. \& Gilpin, M.E.) San Diego: Academic Press, p. 123-47. http://dx.doi.org/10.1016/B978-012323445-2/ $50009-2$

OTTO, S.B., BERLOW, E.L., RANK, N.E., SMILEY, J. \& BROSE, U. 2008. Predator diversity and identity drive interaction strength and trophic cascades in a food web. Ecology 89:134-4. http://dx.doi. org/10.1890/07-0066.1

PACE, M.L., COLE, J.J., STEPHEN, R., CARPENTER, J.F. \& KITCHELL, J.F. 1999. Trophic cascades revealed in diverse ecosystems. Trends Ecol. Evol. 14(12):483-88. http://dx.doi.org/10.1016/S01695347(99)01723-1

PAINE, R.T. 1966. Food webs: road maps of interactions or grist for theoretical development. Ecology 69:1648-54. http://dx.doi.org/10.2307/ 1941141

PARDINI, R., BUENO, A.D., GARDNER, T.A. PRADO, P.I. \& METZGER, J.P. 2010. Beyond the Fragmentation Threshold Hypothesis: Regime Shifts in Biodiversity Across Fragmented Landscapes. Plos One 5(10):e13666. http://dx.doi.org/10.1371/journal.pone. 0013666

PAULY, D., CHRISTENSEN, V., DALSGAARD, J., FROESE, R. \& TORRES, F. 1998. Fishing down marine food webs. Science 279:860-63. http://dx.doi.org/10.1126/science.279.5352.860

PRAKASH, S. \& DE ROOS, A.M. 2002. Habitat destruction in a simple predator-prey patch model: How predators enhance prey persistence and abundance. Theor. Popul. Biol. 62:231-49. http://dx.doi.org/10.1006/tpbi.2002.1611

RUSHTON, S.P., BARRETO, G.W., CORMACK, R.M., MACDONALD, D.W. \& FULLER R. 2000. Modelling the effects of mink and habitat fragmentation on the water vole. J. Appl. Ecol. 37:475-90. http://dx.doi.org/10.1046/j.1365-2664.2000.00504.x

RYALL, K. \& FAHRIG, L. 2006. Response of predators to loss and fragmentation of prey habitat: a review of theory. Ecology 87(5):086-93. http://dx.doi.org/10.1890/0012-9658(2006) 87[1086: ROPTLA]2.0.CO;2

SCHNEIDER, M.F. 2001. Habitat loss, fragmentation and predator impact: spatial implications for prey conservation. J. Appl. Ecol. 38:720-35. http://dx.doi.org/10.1046/j.1365-2664.2001.00642.x

SCHOENER, T.W. \& SPILLER, D. 2010. Trophic Cascades on Islands. In TERBORGH, J. \& ESTES, J.A. Trophic Cascades: Predators, Prey, and the Changing Dynamics of Nature. Island Press, Washington, $488 \mathrm{p}$.

SICK, H. 1997. Ornitologia Brasileira. Rio de Janeiro, Nova Fronteira. S. A., 912 p.

SIGRIST, T. 2006. Aves do Brasil: uma visão artística. São Paulo, Avis Brasilis Editora, $672 \mathrm{p}$.

SINCLAIR, A.R.E., MDUMA, A.S. \& BRASHARES, J.S. 2003. Patterns of predation in a diverse predator-prey system. Nature 425:288-90. http://dx.doi.org/10.1038/nature01934

SOUZA, C. 2003. Mapping forest degradation in the Eastern Amazon from SPOT 4 through spectral mixture models. Remote Sens. Environ. 87:494-506. http://dx.doi.org/10.1016/j.rse.2002.08.002 
STEWART, W.J. 1985. Habitat selection in raptorial birds. In CODY, ML. Habitat selection in birds. San Diego, Academic Press inc,

STOTZ, D.F., FITZPATRICK, J.W., PARKER III, T.A. \& MOSKOVITZ D.K. 1996. Neotropical birds: Ecology and conservation. Chicago, Univ. Chicago Press.

STRONG, D.R. 1992. Are Trophic Cascades all wet? Differentiation and Donor-Control in Speciose Ecosystems. Ecology 73(3): 747-54. http://dx.doi.org/10.2307/1940154

SWIHART, R.K., FENG, Z., SLADE, N.A., MASON, D.M. \& GEHRING, T.M. 2001. Effects of habitat destruction and resource supplementation in a predator-prey metapopulation model. J. Theor. Biol. 210:287-303. http://dx.doi.org/10.1006/jtbi.2001.2304

TERBORGH, J. \& FEELEY, K. 2010. Propagation of Trophic Cascades via multiple pathways in Tropical Forests. In Trophic Cascades: Predators, Prey, and the Changing Dynamics of Nature (Terborgh, J. \& Estes, J.A.) Island Press, Washington, 488 p.

TERBORGH, J., HOLT, R.D. \& ESTES, J.A. 2010. Trophic Cascades: What They Are, How They Work, and Why They Matter. In Trophic Cascades: Predators, Prey, and the Changing
Dynamics of Nature (Terborgh, J. \& Estes, J.A.) Island Press, Washington, $488 \mathrm{p}$.

VIRGÓS, E. \& GARCÍA, F.J. 2002. Patch occupancy by stone martens Martes foina in fragmented landscapes of central Spain: the role of fragment size, isolation and habitat structure. Acta Oecol. 23:231-37. http://dx.doi.org/10.1016/S1146-609X(02) 01142-6

WANGCHUK, T. 2004. Predator-prey dynamics: The role of predators in the control of problem species. Journal of Bhutan Studies 10: $68-89$.

WOLFE, J.D., STOUFFER, P.C., MOKROSS, K., POWELL, L.L. \& ANCIÃES, M.M. 2015. Island vs. countryside biogeography: an examination of how Amazonian birds respond to forest clearing and fragmentation. Ecosphere 6(12):1-14. http://dx.doi.org/10.1890/ ES15-00322.1

ZANDEN, J.V.M., OLDEN, J.D. \& GRATTON, C. 2006. Food-Web Approaches in Restoration Ecology. In Foundations of restoration ecology (FALK, D.A. et al., eds), Island Press, Washington, $378 \mathrm{p}$. 